Abstracta Iranica Abstracta Iranica

Revue bibliographique pour le domaine irano-aryen

Volume 40-41 | 2019

Comptes rendus des publications de 2017-2018

\title{
Yuka Kadoi. "Chinese and Turko-Mongol elements in Ilkhanid and Timurid arts: part 1: the Mongols
}

(c. $1250-1350 "$

Frantz Chaigne

(2) OpenEdition

Journals

Édition électronique

URL : http://journals.openedition.org/abstractairanica/47937

DOI : 10.4000/abstractairanica.47937

ISBN : 1961-960X

ISSN : 1961-960X

Éditeur :

CNRS (UMR 7528 Mondes iraniens et indiens), Éditions de l'IFRI

Référence électronique

Frantz Chaigne, «Yuka Kadoi. "Chinese and Turko-Mongol elements in Ilkhanid and Timurid arts: part

1: the Mongols (c. $1250-1350 "$ ", Abstracta Iranica [En ligne], Volume 40-41 | 2019, document 6, mis en ligne le 15 juillet 2019, consulté le 19 avril 2021. URL : http://journals.openedition.org/

abstractairanica/47937 ; DOI : https://doi.org/10.4000/abstractairanica.47937

Ce document a été généré automatiquement le 19 avril 2021

Tous droits réservés 


\title{
Yuka Kadoi. "Chinese and Turko- Mongol elements in Ilkhanid and Timurid arts: part 1: the Mongols (c. $1250-1350 "$
}

\author{
Frantz Chaigne
}

\section{RÉFÉRENCE}

Yuka Kadoi. "Chinese and Turko-Mongol elements in Ilkhanid and Timurid arts: part 1: the Mongols (c. 1250 -1350" in Finbarr B. Flood, Gülru Necipoğlu (eds.). A Companion to Islamic Art and Architecture. Chichester: Wiley-Blackwell, 2017, vol. 2, p. 636-651

1 Reconnue pour son travail sur la problématique des transferts culturels et matériels entre l'Iran médiéval et l'Extrême Orient, Yuka Kadoi est déjà l'auteure de plusieurs articles sur ce thème ainsi que d'un ouvrage issu de sa thèse (Islamic Chinoiserie: The Art of the Mongol Iran, 2009). Dans la présente contribution qui se veut synthétique, elle propose une approche originale, tirant prétexte de divers médias pour les mettre en regard avec des problématiques qu'ils illustrent significativement: "Textiles as Political Legitimacy and Cultural Identity ", "Ceramics, Miscellaneous Objects, and the Cycle of Chinoiserie ", "China and the Rise of Manuscript Painting in Iran " et "Multireligious Ingredients in the Picturial Arts of Ilkhanid Iran ». Cette méthodologie, qui évite tout discours redondant, se montre à la fois attractive et pertinente eut égard au format restreint inhérent à ce genre d'exercice. De façon concise mais démonstrative, les apports culturels et iconographiques des Mongols sont en effet mis en évidence par des discussions autour d'exemples précis et judicieux. Sans être exhaustive, la bibliographie accompagnant l'article cite les principales références utiles à tout lecteur désireux d'approfondir le sujet. Un seul regret: le terme de «chinoiserie » est employé de façon quasi instinctive sans être davantage défini ou 
problématisé. Ce point accessoire n'enlève toutefois rien à cette introduction à l'art en Iran sous domination mongole.

\section{AUTEURS}

\section{FRANTZ CHAIGNE}

Chercheur associé, CNRS, Orient \& Méditerranée-«Islam médiéval» 